\title{
"A nice brain teaser"
}

\author{
Alice Ashcroft \\ Lancaster University \\ Lancaster, United Kingdom \\ alice.ashcroft@lancaster.ac.uk
}

\begin{abstract}
EN)
Careers in computing seem to be well placed to allow gender parity. The tools of the trade don't require any of the most common gender stereotypes. And yet, talented, educated women avoid going into the field - why? The preliminary research reported in this paper focuses specifically on computer programming, since coding is an area that has shown a strong statistical bias towards males with up to $92 \%$ of programmers being male. This paper aims to uncover and examine any differences in the coding abilities and approach of males and females.
\end{abstract}

\section{KEYWORDS (EN)}

Women, Computing, Gender, Stereotypes, Programming, Traits, Personality, Skills, Code, Ability

\section{CCS CONCEPTS}

Alice Ashcroft 2018. A nice brain teaser. In Proceedings of 4th Gender\&IT conference, Heilbronn, Germany (GenderIT'18). ACM, New York, NY, USA, 4 pages. https://doi.org/10.1145/3196839.3196848

\section{INTRODUCTION}

Whichever way the statistics are viewed, fewer women are finding their way into IT careers and since the mid 80s the numbers have been falling, which is significantly true in the US [4]. Governments and educational bodies have long recognised this as a significant problem [9]. Careers in computing seem to be well placed to allow gender parity. The tools of the trade don't require any of the most common gender stereotypes. And yet, talented, educated women avoid going into the field - why? The preliminary research reported here focuses specifically on computer programming, since coding is an area that has shown a strong statistical bias towards males with up to $92 \%$ of programmers being male

Permission to make digital or hard copies of part or all of this work for personal or classroom use is granted without fee provided that copies are not made or distributed for profit or commercial advantage and that copies bear this notice and the full citation on the first page. Copyrights for third-party components of this work must be honored. For all other uses, contact the owner/author(s).

GenderIT, May 14-15, 2018, Heilbronn, Germany

(C) 2018 Association for Computing Machinery.

ACM ISBN 978-1-4503-5346-5/18/05 ...\$15.00

https://doi.org/10.1145/3196839.3196848
[5]. This paper aims to uncover and examine any differences in the coding abilities and approach of males and females.

\section{LITERATURE REVIEW}

Baser [2] draws upon research from Facey-Shaw and Golding to state; "since students' attitude towards programming may yield increased performance and appreciation ... we need to increase students' attitude toward programming". The stereotypical image of a "programmer" is perhaps not a personality type that most people aspire to be and programming may be an isolated role, and social interaction appears limited. Ullman [8], suggests there are 2 main attributes anyone must have to succeed as a programmer. The first of these is "a passion for the work", the second is that to succeed in the field of computing a person must have "a high tolerance for failure". Programming is a constant stream of trial and error; to be able to fail and then continue may be the most important attribute a programmer can have [3].

Much less research has considered the skills a programmer must have to be successful in completion of tasks, rather than simple personality traits. Bailey and Stefaniak [1] suggest the skills ranked most highly by professionals, besides basic programming abilities include "listening skills", "team work skills (long term)" and the "ability to visualize/conceptualize". Interestingly, these skills are skills stereotypically associated with women, not men. Other research has also identified high skill levels in women programmers. Terrell et al. [7] found that pull requests on GitHub projects created by women were the most accepted and highly rated. Saujani [6] states that "it turns out that our girls are really good at coding, but it's not enough just to teach them to code", she suggests that women are taught to be perfect, whilst men are taught to take risks and act bravely. Perhaps it is not women's ability to code that holds them back but the opportunities they are provided with. Burn-Callander [10] suggests that it is schools teaching programming in a rigid way with no opportunity to enhance imagination that is stopping women entering the field of computing. She suggests that if a pupil is given opportunity to be creative when programming or learning concepts then, regardless of gender, the pupil will thrive.

\section{METHODOLOGY}

In this study, a mixed method was used, with three forms of data combined to create a more complete overview of each 
participant and their experiences of programming. The first of these was a programming task. The programming task allowed the code to be reviewed to detect any differences between the male and female groups. The second part was an observation of how participants interacted and discussed the task. The final part of the experiment consisted of group interviews/focus groups in which the participants were asked about the task and their experiences

The programming task was designed with first year undergraduate students in mind, to ensure that all participants had the knowledge necessary to be able to complete the task. All participants were recruited through a survey sent to all students in the department. The four groups, undergraduate (UG) and postgraduate (PG) men and women, were given an incomplete game of "Noughts and Crosses" and were asked to implement the game logic (part 1), and to improve the user interface of the game (part 2). However, creativity was not the focus of the study, this was the programming itself. All libraries needed had been imported, and comments in the code had been made explaining what the existing code did and where to implement the game logic. All tasks and interviews were video recorded and transcribed. The format of the study was such that each group would receive 30 minutes to complete the programming task and each was followed by a group interview. The semi-formal interviews were carried out in the 30 minutes following the task, so that memories of the task would still be at the forefront of their minds and allowed for the possibility of participants triggering responses from other participants and being more open about the experience. Discussion questions asked after the programming task included, but were not limited to:

When you're set a programming task, how do you go about it? What do you do first? The easy parts? The parts that make the most sense? Did you work as a team equally or did someone take the lead? How did you decide who that was? The task was in two sections, which did you go about first? Why? Which part was most enjoyable? Which part was easier?

The focus groups and interviews were analysed using a thematic inductive approach; each interview transcript was read in detail and emerging themes were recorded.

\section{RESULTS}

Overall, the code that was produced by the female groups was arguably more efficient and elegant. Perhaps the most interesting result was the way the men approached the task against women. The two male groups both decided to use switch cases as the most effective way to complete the task in the time given, which could be suggested as being significantly "hack" like. The female participants talked about recursion and speculated about how they could write an algorithm to complete the task - a more efficient and scalable method. This, combined with differences in groupwork, leadership, confidence and their reflections on the task, indicated that there were many differences between the male and female participants.

\subsection{Approaching the task}

The UG men who attempted the task aggressively blamed the code they had been given, unlike the PG men who described the task as easy but blamed themselves for over complicating it, and spending "a bunch of time [on] something that didn't need it". The UG women described the task as "really hard" and "difficult" as did the PG women who describe the task as being difficult, with one describing it as "a nice brain teaser", suggesting an element of enjoyment. When asked if they found the task enjoyable, the UG women as a group said no but an individual in the group, the leader in the task, said they "enjoyed figuring out the maths" and enjoyed the logical side of this, as did all the PG women. The PG men discussed with each other what they were going to do and from observation, they drew out diagrams to explain their ideas. The PG women described their approach to a task as they "get down what we need to do" and in this task "drawing it really helped". The UG men said they "like to draw things out and plan it out", which they did not do when carrying out the task set. One of them was perhaps more honest and said "I just tend to start, and that always gets me into problems later".

The UG women said they normally "break it down into smaller bits" and focus on "the parts that build the foundation" but in this case they seemed to go backwards and forwards between game logic and improving the UI, suggesting they had no clear strategy. The PG men said they "always try and get the minimum viable product all done first" and want to just get "something working". The PG women agreed saying; "there's no point having a game that's not playable" as did the UG Men saying they start "from which are most necessary to the game". They all seemed to agree, in theory, that having a minimum viable product (MVP) is the first thing that should be worked towards. However, not all groups managed to put this into practice. The only two groups who mentioned using recursion - the most efficient and scalable way of carrying out this task - were the women. Both groups discussed using this during the activity but both male groups decided that they were going to hardcode each case to get it completed in the time.

\subsection{Group work}

The PG men seemed to have the most experience working on tasks in groups and they discussed pair programming and how working together slowed development but created better code. Both the PG men and women discussed the task as they went along, valuing the inputs of others and debating better options within the group, coming to a decision and then pursuing that course. The differences between the discussions 
between the groups was that the women spent longer discussing in comparison to the men who, when they reached something they couldn't agree on, had the leader make the decision for the group. This may have allowed the PG men group to get further with the task, had they not become blocked on initializing the array lists. The UG and PG women seemed to have similar views on working on existing code and in groups with comments such as; "I don't like reading other people's code". The PG women preferred to work as individuals as they felt that in groups people "don't wanna listen" and "sometimes it's just best to keep yourself to yourself". They then related this to the ability of the team members, saying that "when there's people of different abilities in a group, it can be a bit detrimental".

\subsection{Leadership}

Both male groups had a self-elected leader, both were for seemingly irrelevant reasons, nothing to do with ability but due to where they were sat or their familiarity with the type of computer the task was carried out on. This is strongly supported by the work carried out by Zingalesd et al. [15], who commented that men often achieve leadership roles regardless of past, remembered and claimed performance. The UG women jointly agreed a leader through discussion based on ability whereas the PG women all worked in a team equally when carrying out the task.

\subsection{Reward and Confidence}

The PG men all seemed in agreement that getting a functional system working is "rewarding" adding that "if it's doable, but hard, that's probably always going to be more enjoyable". Similarly, the PG women said, "when you get something to work it builds your confidence". Both PG groups all said they enjoyed the harder tasks because they felt these were more rewarding. The PG women stated that "there's nothing rewarding about doing something everyone can do", like the leader of the UG women who preferred tasks that are more difficult because "it feels really rewarding ... I'm really happy when I've done it". The way in which the PG woman explained this was very informative, they did not say they enjoyed hard tasks, but that they like the idea of being able to do something that others could not, suggesting that they appreciated the superiority of being able to complete these tasks, saying that it meant they would "go home feeling really good". This ties into work by Rowe [13] showing that with girls "correlations between measures of achievement and confidence in learning mathematics were greatest", and this may be the trend across all STEM subjects. The PG women mentioned how they did not work as well under pressure and certainly do not enjoy it as much, supporting Sullivan and Bers [14] who suggest girls' experience with Computing and Education is negatively impacted by the pressure to succeed and successfully complete tasks at the first attempt. It may be worth noting that two of the PG women, after the study, asked for the code as they were frustrated with themselves for not completing the task in the time allocated.

\section{CONCLUSION}

In approaching the task the men and women had very different tactics. Both groups of women mentioned using recursion to resolve the issue when carrying out the tasks. The women were therefore debating a more elegant solution to the problem, which would have been more efficient and scalable. This speaks volumes and perhaps suggests that women write more elegant code, even if this will take longer. Whereas the male participants chose the fastest solution that simply gets the job done. Of course, the results obtained in this study are most certainly suggestive and not conclusive, but the sample size is not so small that we cannot make assumptions [11]. These studies should be run on a larger scale with mixed groups, and with different genders of coordinators and interviewers for each study. The time that was given to the students in this instance was not long enough to provide code that could be analysed in great detail, however future studies should also use code that was produced in the study to see if the style itself was any different between the genders on a line by line level.

It has been suggested that stereotypes such as working in isolation and the "perception of programming as an idiosyncratic arcane discipline" [12] is what has deterred women from entering the field and that due to these stereotypes women choose to not enter the field. The suggestion that women need to be like men in order to succeed in programming is preposterous. Instead the characteristics of women, stereotypical or not, should be used to the advantage of STEM subjects, including computing. The ability to think logically and with persistence can be found across all genders, so why should this effect a woman's ability to program effectively?

\section{REFERENCES}

[1] Janet L. Bailey and Greg Stefaniak. 2017. Industry perceptions of the knowledge, skills, and abilities needed by computer programmers, pp. 93-99, 10.1145/371209.371221

[2] Mustafa Baser. 2013. 'Attitude, gender and achievement in computer programming', Online Submission, 14(2), pp. 248-255.

[3] Carol Dweck. 2012. Mindset. 1st ed. Robinson, London.

[4] Thomas J. Misa. 2010. Gender codes Defining the problem. Available at: http://www.tc.umn.edu/\%7Etmisa/papers/2010_WileyGenderDefining.pdf (Accessed: 7 November 2016).

[5] Kevin Roose. 2015. Survey says: 92 percent of software developers are men. Available at: http://fusion.net/story/115998/survey-says-92percent-of-software-developers-are-men/ (Accessed: 3 March 2017).

[6] Reshma Saujani. 2016. Teach girls bravery, not perfection. Available at: https://www.ted.com/talks/reshma_saujani_teach_girls_bravery_not_pe rfection/transcript?language=en (Accessed: 23 November 2016).

[7] Josh Terrell, Andrew Kofink, Justin Middleton, Clarissa Rainear, Emerson Murphy-Hill, Chris Parnin and Jon Stallings. 2016. 'Gender differences and bias in open source: Pull request acceptance of women versus men', Gender Differences and Bias in Open Source: Pull Request Acceptance of Women Versus Men. doi: 10.7287/peerj.preprints.1733v2.

[8] Ellen Ullman. 2017. How to Be a 'Woman Programmer'. [online] Nytimes.com. Available at: 
http://www.nytimes.com/2013/05/19/opinion/sunday/how-to-be-awoman-programmer.html (Accessed: 7 March 2017).

[9] WISE. 2017. Welcome to the WISE campaign. Available at:

https://www.wisecampaign.org.uk/ (Accessed: 3 March 2017).

[10] Rebecca Burn-Callander. 2017. Why women make gifted coders. [online] Telegraph.co.uk. Available at:

http://www.telegraph.co.uk/technology/11643191/Why-womenmake-gifted-coders.html (Accessed 7 March 2017).

[11] Andy Crabtree, Peter Tolmie and Mark Rouncefield. 2013. "How Many Bloody Examples Do You Want?" Fieldwork and Generalisation. In: Bertelsen O., Ciolfi L., Grasso M., Papadopoulos G. (eds) ECSCW 2013 Proceedings of the 13th European Conference on Computer Supported Cooperative Work, pp. 21-25 September 2013, Paphos, Cyprus. Springer, London

[12] Nathan Ensmenger. 2010. Making Programming Masculine. Gender Codes: Why Women Are Leaving Computing, pp.115-141.

[13] Kenneth J. Rowe. 1988. 'Single-sex and mixed-sex classes: The effects of class type on student achievement, confidence and participation in mathematics', Australian Journal of Education, 32(2), pp. 180-202. doi: 10.1177/000494418803200204.

[14] Amanda Sullivan and Marina U. Bers. 2012. 'Gender differences in kindergarteners' robotics and programming achievement', International Journal of Technology and Design Education, 23(3), pp. 691-702. doi: 10.1007/s10798-012-9210-z.

[15] Luigi Zingales, Ernesto Reuben, Pedro Rey-Biel and Paola Sapienzac. 2012. The emergence of male leadership in competitive environments. Available at:

http://www.sciencedirect.com/science/article/pii/S016726811100161 2 (Accessed: 13 February 2017). 